\title{
Research Paper: Effects of Personality Traits and Perfectionism in Predicting Core Self-evaluations of Women With Trichotillomania and Healthy Women
}

\author{
Solmaz Azizi ${ }^{1 *}$, Mir Taghi Garoosi Farshi ${ }^{1}$, Hamid Poursharifi ${ }^{2}$, Shirin Farazmand ${ }^{3}$ \\ 1. Department of Clinical Psychology, Faculty of Humanities, Tabriz Branch, Islamic Azad University, Tabriz, Iran. \\ 2. Department of Psychology, Faculty of Education and Psychology, University of Tabriz, Tabriz, Iran. \\ 3. Department of Clinical Psychology, University of Social Welfare and Rehabilitation Sciences, Tehran, Iran.
}

\begin{tabular}{|c|c|}
\hline Use your device to scan & \\
\hline and read the a & Citation: Azizi, S., Garoosi Farshi, M. T.. Poursharifi. H.. \& F \\
\hline & tionism in Predicting Core Self-evaluations of Women With Trichotillomania and Healthy Women. Journal of Practice in Clinical \\
\hline 10 & Psychology, 5(2), 123-132. https://doi.org/10.18869/acadpub.jpcp.5.2.123 \\
\hline 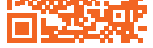 & doi): https://doi.org/10.18869/acadpub.jpcp.5.2.123 \\
\hline
\end{tabular}

Article info:

Received: 07 Oct. 2016

Accepted: 30 Jan. 2017

Keywords:

Personality, Perfectionism, Evaluation, Trichotillomania, Women

\section{ABSTRACT}

Objective: This study aimed to investigate the effects of the personality traits and perfectionism in predicting core self-evaluations of women with trichotillomania and healthy women.

Methods: This was a cross-sectional study. A total of 50 women affected with trichotillomania (age-matched with 50 normal women) were selected by convenience sampling method from counseling centers of Tabriz City, Iran. The participants completed the NEO Five Factor Inventory, perfectionism, and core self-evaluation scales. Data were analyzed by the stepwise multiple regression using SPSS16.

Results: The results indicated that the neuroticism and conscientiousness traits predict core self-evaluations in the normal women. Moreover, the neuroticism and openness to experience also predicted the core self-evaluation in those with trichotillomania, while the perfectionism could not predict core self-evaluation.

Conclusion: In this study, findings showed that personality traits contribute to predict core self-evaluations of women with trichotillomania and healthy women.

\section{Introduction}

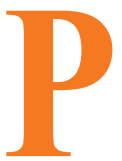

ersonality is a construct characterized by a complicated pattern of deeply individual characteristics that affects most areas of psychological functions (Millon, Millon, Migher, Grossman, \& Ramnath, 2004). In other words, personality is a psychological organization that determines individual's thoughts and behaviors
(Schultz \& Schultz, 2012). Personality can be broken into components that are called personality traits, including openness to experience, conscientiousness, extraversion, agreeableness, and neuroticism. Costa and McCrae believed that personality traits could be responsible for many behaviors and characteristics of individuals (Costa $\&$ McCrae, 1985). Several studies revealed that the effects of personality traits on psychological disorders and maladaptive behaviors are prominent (Bleek, Montag, Faber \&

* Corresponding Author:

Solmaz Azizi, MSc.

Address: Department of Clinical Psychology, Faculty of Humanities, Tabriz Branch, Islamic Azad University, Tabriz, Iran.

Tel: +98 (914) 3124535

E-mail: solmazazizi3415@yahoo.com 
Reuter, 2011; Moroz \& Dunkley, 2015). Trichotillomania is one of these disorders that besides damaging psychological functions, impairs physical health such as appearance (Boudjouk, Woods, Miltenberger, \& Long, 2000; Flessner, Woods, Franklin, Keuthen, \& Piacentini, 2009; Franklin et al., 2008; Tay, Levy, \& Metry, 2004; Tolin, Franklin, Diefenbach, Anderson, \& Meunier, 2007).

Trichotillomania is a repetitive, chronic, debilitating period of pulling out one's own hair from scalp, eyebrows, eyelashes, or other areas. Based on DSM-IV-TR classification, trichotillomania was as an impulse control disorder (not classified elsewhere). However, in the DSM-5, trichotillomania is inserted in obsessive compulsive and related disorders category and the term "hair pulling disorder" has been added to the disorder's name. This change signifies the important similarity between trichotillomania and $\mathrm{Ob}$ sessive-Compulsive Disorder (OCD) (Rufer et al., 2014).

Also, many studies revealed that trichotillomania is accompanied with negative psychosocial consequences such as low self-esteem, feelings of shame, and avoidance of social activities (Diefenbach, Tolin, Meunier, \& Worhunsky, 2008; Woods, Flessner, Franklin, Keuthen et al., 2006). Investigators suggested that these consequences may be particularly associated with comorbid OCD or depression with trichotillomania that are often related to a "tendency toward perfectionism" (Mansueto, Golomb, Thomas, \& Stemberger, 1999). Perfectionism is a personality characteristic described by setting extremely high standards for performance that is accompanied by critical self-evaluation and concern about other's evaluations (Stoeber \& Childs, 2010; Flett \& Hewitt, 2002). Although several self-help books written by researchers and therapists, e.g., Keuthen, Stein, \& Christianson, 2001; Penzel, 2003, on trichotillomania indicate a connection between trichotillomania and perfectionism, most of the studies have stressed on OCD and perfectionism, and only one article has investigated the association of perfectionism with trichotillomania so far (Pelissier \& O'Connor, 2004).

On the other hand, previous research has revealed that hair pulling behavior in trichotillomania disorder has an emotion regulation function and is a coping response style (Diefenbach, Tolin, Meunier, \& Worhunsky, 2008; Shusterman, Feld, Baer, \& Keuthen, 2009). The processes of coping with stress and the emotion regulation play an important role in the development of psychopathology (Compas et al., 2014). In consistent with these findings, the patients with trichotillomania usually pull hair to reduce their tension. In addition, stressful situations which are associated with unpleasant emotions usually stimulates hair pulling behavior which reflects maladap- tive coping style (Shusterman et al., 2009; Teng, Woods, Twohig, \& Marcks, 2002; Diefenbach et al., 2008).

Although there are various explanations for why some individuals successfully manage stressful situations and some not, several organizational behavior investigators have emphasized the role of self-esteem, locus of control, and emotional stability in coping (Spector, Zapf, Chen, \& Frese, 2000). Self-esteem, locus of control and emotional stability are closely related to the concept described as core self-evaluation (Judge \& Ilies, 2002). Core self-evaluation is a useful unifying framework for understanding individual diversity in the appraisal and response to the stressful situations. Core self-evaluation is a complex concept that includes self-evaluation of own self-worth, competence, and abilities, which is composed of 4 personality traits: self-esteem, locus of control, generalized self-efficacy, and neuroticism (Judge, Locke, Durham, \& Kluger, 1998). These personality traits indicate the self-appraisal of personal competence, appraisal of own emotional functioning and control. Previous studies indicate that core self-evaluation is strongly and positively correlated with well-being (Brunborg, 2008; Yan \& Su, 2012). In other words, individuals with positive core self-evaluations appraise themselves in a consistently positive manner across situations; such individuals see themselves as capable, worthy, and in control of their lives, so they are less prone to psychological disorders (Judge, VanVianen, \& de Pater, 2004).

Although previous studies on trichotillomania have been focused on predisposing factors, the role of personality traits and perfectionism in the development of core self-evaluation of patients with trichotillomania had been neglected and needed more research. Thus based on previous research, the present study aimed to investigate the role of personality traits and perfectionism in predicting core self-evaluations of women with trichotillomania and normal ones.

\section{Methods}

This was a descriptive-correlational and cross-sectional study. The study population comprised all women aged between 20 and 50 years living in Tabriz City. The sample consists of 50 patients meeting DSM-IV diagnostic criteria for trichotillomania and 50 normal participants. Subjects were selected by convenience sampling method from counseling centers of Tabriz and then referred to Azad University of Tabriz to identify clinical and subclinical trichotillomania. Subjects were recruited over a 3-year period (2012-2015). 
Inclusion criteria were as follows: 1) having the diagnostic criteria of trichotillomania based on DSM-IV; 2) being woman; 3) aged between 20 and 50 years. Furthermore, normal participants were being women who matched by gender, age and education with patient group. The exclusion criteria were reluctance to participate in the study and having past or present psychosis. After obtaining permission from these centers, individuals were diagnosed. Then all participants were informed about the purposes of the study and received the instructions of filling out the questionnaires. Participants agreed to take part in a study on investigating the effects of personality trait and perfectionism on trichotillomania, while they were free to leave the study whenever they want. Afterwards, they completed the questionnaires. Finally, data of 100 participants were used in analysis.

Study instruments are Core Self-Evaluations Scale and NEO Five-Factor Inventory (NEO-FFI). The Core SelfEvaluations Scale (CSES) (Judge, Erez, Bono, \& Thoresen, 2003) is a 12-item questionnaire designed to assess the underlying self-evaluative factor. This scale consists of 4 subscales of self-esteem, generalized self-efficacy, neuroticism, and locus of control. The participants were asked to respond to items on a 5-point Likert-type scale ranging from $1=$ strongly disagree to $5=$ strongly agree. The higher score indicates higher core self-evaluation. In Judge et al. (2003) study, the internal consistency of the scale was good, $\alpha=0.80$ (2003). The Cronbach $\alpha$ coefficients in another study for 4 discrete groups were between 0.80 and 0.84 (Sharati, Garosi, Babapour, 2010). In this study, the scale had a Cronbach $\alpha$ coefficient of 0.79 .

NEO Five-Factor Inventory (NEO-FFI) (Costa \& McCrae, 1992) consists of 60 items with a 5-Likert scale response format ( $0-4$ points). This scale was designed to measure the personality dimensions, including extraversion, neuroticism, openness to experience, conscientiousness, and agreeableness; their coefficient $\alpha$ values were reported as $0.92,0.89,0.87,0.86$, and 0.90 , respectively (Costa \& McCrae, 1992). In other studies, the reliability of this scale was 0.53 to 0.87 (Besharat, 2005).

Multidimensional perfectionism questionnaire (Hewitt \& Flett, 1990) is a 45-item scale (Hewitt \& Flett, 2004) used to determine socially prescribed, other-oriented, and selfdirected perfectionism. It has exhibited satisfactory reliability and validity in numerous studies, e.g., Hewitt \& Flett, 2004. The Persian version of multidimensional perfectionism questionnaire has high internal consistency (Cronbach $\alpha=0.91$ ) and acceptable test-retest reliability, $\mathrm{r}=0.85$ (Soofiani, 2007). The current sample also demonstrated adequate internal consistency and acceptable test-retest reliability in socially prescribed perfectionism (Cronbach $\alpha=0.81, r=0.60$ ), other-oriented perfectionism (Cronbach $\alpha=0.74, \mathrm{r}=0.66$ ), and self-directed perfectionism (Cronbach $\alpha=0.88, r=0.69$ ). Participants were asked to what degree they agreed with each statement and responded on a scale from 1 (strongly disagree) to 7 (strongly agree).

Statistical analysis was performed using the SPSS16. In order to analysis the data, we used descriptive (mean and standard deviation) and inferential statistics (multiple regression by stepwise method). At first, the Pearson correlation was assessed to examine the relationship between study variables. After that, a stepwise regression analysis was performed in order to determine the proportion of personality traits and perfectionism in predicting core self-evaluation in women with trichotillomania and normal women $(\mathrm{P}<0.05)$.

\section{Results}

Table 1 shows the mean and standard deviation of personality traits, perfectionism, and core self-evaluation in normal and trichotillomania women. Based on the result of variance homogeneity test, except other-directed perfectionism (other-oriented perfectionism $\mathrm{F}=4.014, \mathrm{P}=0048$ ), variance of other variables between two groups are homogenous. Table 2 presents the results of independent $t$ test between patients with trichotillomania and healthy individuals. Based on significance of t-test, the difference between groups in neuroticism, self-directed perfectionism, socially prescribed perfectionism, total perfectionism and core self-evaluation are significant. But with respect to extraversion, openness to experience, agreeableness, and conscientiousness, the difference is not significant.

Regression analysis by stepwise method was used to determine the proportion of personality traits and perfectionism in explaining the variance of core self-evaluation in women with trichotillomania and normal women. Results are summarized in Table 4 and 6.

Table 3 and Table 5 show the Pearson correlation among variables. Table 3 shows the Pearson correlation test among all variables of normal women and Table 5 shows result of the Pearson correlation test among all variables of women with trichotillomania.

At first we tested multiple regression statistical assumption by checking for multivariate outliers with the Mahalanobis distance. Based on this outcome, no cases was eliminated from the analysis. After that, we assessed collinearity statistics and our result showed that the tolerance of all the predictors are far in excess 0.01 suggesting that multicollinearity is not a problem. 
According to Table 4 when neuroticism enters the regression, adjusted $\mathrm{R}^{2}$ is 0.39 , which means that $39 \%$ of the variance of core self-evaluation of normal women is explained by neuroticism. In the next step, conscientiousness is entered and adjusted $\mathrm{R}^{2}$ is 0.43 , which means that neuroticism and conscientiousness can explain $43 \%$ of the variance of core self-evaluation of normal women. In the present study, the equation representing the prediction model is this:

Core self-evaluation of healthy women $=-0.59$, neuroticism; and $=+0.22$, conscientiousness, meaning that when the score of neuroticism increases one point, the mean severity of core self-evaluation of normal women decreases 0.59 point and also one point increase in conscientiousness corresponds to 0.22 rise in core self-evaluation of normal women.
According to Table 6, when neuroticism enters the regression, adjusted $\mathrm{R}^{2}$ is 0.31 , which means that $31 \%$ of the variance of core self-evaluation of healthy women is explained by neuroticism. In the next step, openness to experience is entered and adjusted $\mathrm{R}^{2}$ is 0.40 , which means that neuroticism and openness to experience can explain $40 \%$ of the variance of core self-evaluation of women with trichotillomania in the present study.

\section{Discussion}

The present study aimed to investigate the role of personality traits and perfectionism in predicting core self-evaluations of women with trichotillomania and normal women. Results showed that the neuroticism trait and conscientiousness can predict the core self-evaluations in the nor-

Table 1. The means and standard deviation of variables

\begin{tabular}{|c|c|c|c|c|}
\hline \multicolumn{3}{|c|}{ Variable } & Mean & SD \\
\hline \multirow{11}{*}{ Personality traits } & \multirow{6}{*}{ Healthy women } & Neuroticism & 20.6 & 8.08 \\
\hline & & Extraversion & 28.84 & 5.86 \\
\hline & & Openness to experience & 29.96 & 5.22 \\
\hline & & Agreeableness & 31.18 & 6.73 \\
\hline & & Conscientiousness & 34.72 & 7.65 \\
\hline & & & & \\
\hline & \multirow{5}{*}{$\begin{array}{l}\text { Women with } \\
\text { trichotillomania }\end{array}$} & Neuroticism & 24.32 & 7.78 \\
\hline & & Extraversion & 26.80 & 6.13 \\
\hline & & Openness to experience & 31.34 & 5.54 \\
\hline & & Agreeableness & 30.24 & 6.60 \\
\hline & & Conscientiousness & 33.28 & 6.23 \\
\hline \multirow{11}{*}{ Perfectionism } & \multirow{4}{*}{ Healthy women } & Self-directed perfectionism & 24.18 & 5.81 \\
\hline & & Other-directed perfectionism & 26.86 & 7.43 \\
\hline & & Socially prescribed perfectionism & 24.28 & 6.46 \\
\hline & & Total perfectionism & 75.32 & 16.50 \\
\hline & \multirow{5}{*}{$\begin{array}{l}\text { Women with } \\
\text { trichotillomania }\end{array}$} & Self-directed perfectionism & 29.80 & 6.98 \\
\hline & & & & \\
\hline & & Other- directed perfectionism & 32.18 & 5.57 \\
\hline & & Socially prescribed perfectionism & 28.14 & 6.42 \\
\hline & & Total perfectionism & 90.12 & 14.63 \\
\hline & Healthy women & Core self- evaluation & 44.12 & 6.16 \\
\hline & $\begin{array}{l}\text { Women with } \\
\text { trichotillomania }\end{array}$ & Core self-evaluation & 39.80 & 5.92 \\
\hline
\end{tabular}


Table 2. Result of T-test among all study variables to compare the mean score of women with trichotillomania and healthy individuals

\begin{tabular}{cccccc}
\hline Dependent Variables & $\mathbf{F}$ & P value & $\mathbf{t}$ & df & P value \\
\hline Neuroticism & 0.005 & 0.941 & 2.344 & 98 & 0.021 \\
\hline Extraversion & 0.053 & 0.818 & -1.701 & 98 & 0.092 \\
\hline Openness to experience & 0.728 & 0.396 & 1.281 & 98 & 0.203 \\
\hline Agreeableness & 0.007 & 0.933 & -7.05 & 98 & 0.482 \\
\hline Conscientiousness & 0.389 & 0.534 & -1.032 & 98 & 0.305 \\
\hline $\begin{array}{c}\text { Self-directed perfectionism } \\
\text { Other-directed perfectionism }\end{array}$ & 1.555 & 0.215 & 4.374 & 98 & 0.0001 \\
\hline $\begin{array}{c}\text { Socially prescribed perfectionism } \\
\text { Total perfectionism }\end{array}$ & 0.014 & 0.048 & 4.049 & 98 & 0.0001 \\
\hline Core self- evaluation & 0.004 & 0.952 & 4.746 & 98 & 0.003 \\
\hline
\end{tabular}

mal group, while neuroticism and openness to experience can predict the core self-evaluation in those with trichotillomania. Nevertheless, this hypothesis that perfectionism could predict core self-evaluation was not confirmed in this study. These findings are consistent with previous results demonstrating that trichotillomania disorder is strongly influenced by the perception of individual about stressful situations and their ability to cope (Teng et al., 2002). Trichotillomania disorder is a coping response with an emotion regulation function similar to many psychological disorders such as binge eating, substance abuse, or self-harm which relate to the emotion regulation. And

Table 3. Result of the Pearson correlation test among all variables of normal women

\begin{tabular}{|c|c|c|c|c|c|c|c|c|c|c|}
\hline Variables & 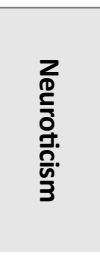 & 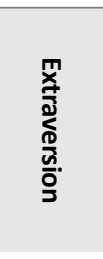 & 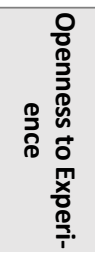 & 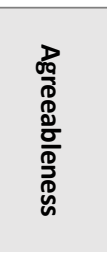 & 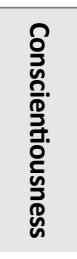 & 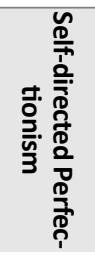 & 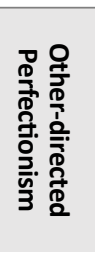 & 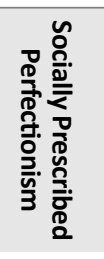 & 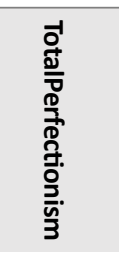 & 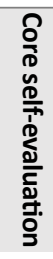 \\
\hline Neuroticism & 1 & & & & & & & & & \\
\hline Extraversion & $-0.42 * *$ & 1 & & & & & & & & \\
\hline Openness to experience & 0.15 & 0.01 & 1 & & & & & & & \\
\hline Agreeableness & -0.2 & 0.25 & $0.47^{* *}$ & 1 & & & & & & \\
\hline Conscientiousness & -0.22 & $0.43^{* *}$ & $0.3^{*}$ & $0.49 * *$ & 1 & & & & & \\
\hline Self-directed perfectionism & $0.38^{* *}$ & -0.22 & -0.05 & $-0.33^{*}$ & -0.11 & 1 & & & & \\
\hline Other-directed perfectionism & $0.38^{* *}$ & $-037^{* *}$ & -0.1 & $-0.43^{* *}$ & -0.13 & $0.54 * *$ & 1 & & & \\
\hline Socially prescribed perfectionism & $0.47^{* *}$ & -0.17 & -0.21 & -0.19 & -0.22 & $0.48^{* *}$ & $0.61^{* *}$ & 1 & & \\
\hline Total perfectionism & $0.49^{* *}$ & $-0.31^{*}$ & -0.15 & $-0.39 * *$ & -0.18 & $0.78^{* *}$ & $0.88^{* *}$ & $0.84^{* *}$ & 1 & \\
\hline Core self- evaluation & $-0.64^{* *}$ & $0.45^{* *}$ & 0.08 & 0.12 & $0.36^{*}$ & -0.25 & $-0.34 *$ & $-0.43^{* *}$ & $-0.41^{* *}$ & 1 \\
\hline
\end{tabular}

${ }^{*} \mathrm{P}<0.05 .,{ }^{* *} \mathrm{P}<0.01$. 
Table 4. Results of stepwise multiple regression for personality traits and perfectionism, predicting core self-evaluation of healthy women

\begin{tabular}{|c|c|c|c|c|c|c|c|}
\hline & \multirow{2}{*}{ Model } & \multirow[t]{2}{*}{$\mathbf{R}^{2}$} & \multicolumn{2}{|l|}{$\begin{array}{l}\text { Unstandardized } \\
\text { Coefficient }\end{array}$} & \multirow{2}{*}{$\begin{array}{c}\text { Standardized } \\
\text { Coefficient }\end{array}$} & \multirow[t]{2}{*}{$\mathbf{T}$} & \multirow[t]{2}{*}{ P Value } \\
\hline & & & B & SE & & & \\
\hline \multirow[b]{2}{*}{ Step 1} & Constant & & 54.19 & 1.86 & & 29.06 & 0.001 \\
\hline & Neuroticism & 0.39 & -0.48 & 0.08 & -0.64 & -5.79 & 0.001 \\
\hline \multirow{3}{*}{ Step 2} & Constant & & 47.06 & 3.88 & & 12.10 & 0.001 \\
\hline & Neuroticism & 0.43 & 0.45 & 0.08 & -0.59 & -5.39 & 0.001 \\
\hline & Conscientiousness & & 0.18 & 0.08 & 0.22 & 2.06 & 0.044 \\
\hline
\end{tabular}

PRACTICE in CLINICAL PSYCH $\odot$ LOGY

that patients with trichotillomania pull their hair to regulate aversive internal experiences (Diefenbach et al., 2008; Grant, Odlaug, \& Potenza, 2007; Shusterman, et al., 2009). Several studies supported these findings that core self-evaluations play an important role in the stress coping strategies (Bolger \& Zuckerman, 1995; Maddi, 1999) and thus are associated with well-being (Klag \& Brad- ley, 2004; Tougas, Rinfret, Beaton, \& de la Sablonniere, 2005). This means that self-esteem and locus of control as subscales of core self-evaluation are associated with better management of stressful situations. Individuals who perceive themselves worthy and capable of coping with stressors could better encounter the situations, whereas individuals who do not see themselves as worthy and capable could not manage their stressful situations well (Judge et al., 1998).

The results of this study also provided some evidence to explain the link between personality traits and core self-evaluation of normal women and those with trichotillomania. Personality traits are related to the specific patterns of behavior and social consequences that can be expected (John \& Srivastava, 1999). Neuroticism is one of these personality traits that reflects individual dif-

Table 5. Result of the Pearson correlation test among all variables of women with trichotillomania

\begin{tabular}{|c|c|c|c|c|c|c|c|c|c|c|}
\hline Variables & 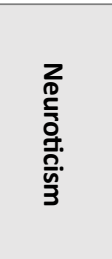 & 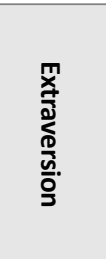 & 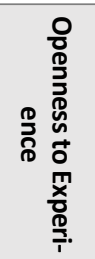 & 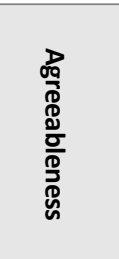 & 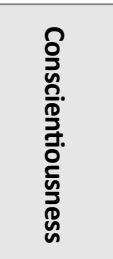 & 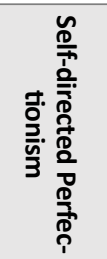 & 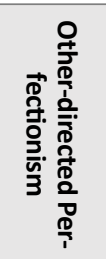 & 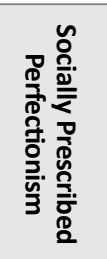 & 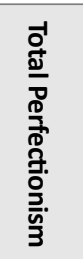 & 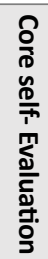 \\
\hline Neuroticism & 1 & & & & & & & & & \\
\hline Extraversion & $-0.35^{*}$ & 1 & & & & & & & & \\
\hline Openness to experience & 0.22 & 0.35 & 1 & & & & & & & \\
\hline Agreeableness & $-0.29 *$ & 0.14 & -0.02 & 1 & & & & & & \\
\hline Conscientiousness & $-0.39 * *$ & $0.54 * *$ & 0.09 & $0.38 * *$ & 1 & & & & & \\
\hline Self-directed perfectionism & $0.43^{* *}$ & -0.82 & 0.14 & $-0.53^{* *}$ & $-0.39 * *$ & 1 & & & & \\
\hline Other-directed perfectionism & 0.2 & 0.04 & 0.04 & $-0.43 * *$ & -0.05 & $0.59 * *$ & 1 & & & \\
\hline Socially prescribed perfectionism & $0.28^{* *}$ & 0.1 & -0.09 & -0.12 & -0.22 & $0.34^{*}$ & 0.23 & 1 & & \\
\hline Total perfectionism & $0.4^{* *}$ & 0.02 & 0.05 & $-0.47^{* *}$ & $-0.3^{*}$ & $0.85^{* *}$ & $0.76 * *$ & $0.69 * *$ & 1 & \\
\hline Core self- evaluation & $-0.58 * *$ & $0.48 * *$ & $0.29 *$ & 0.06 & $0.45 * *$ & -0.11 & 0.07 & $-0.36 *$ & -0.18 & 1 \\
\hline
\end{tabular}

${ }^{*} \mathrm{P}<0.05 .{ }^{* * \mathrm{P}<0.01}$ 
Table 6. Results of stepwise multiple regression for personality traits in predicting core self-evaluation of women with trichotillomania

\begin{tabular}{|c|c|c|c|c|c|c|c|}
\hline \multicolumn{2}{|c|}{ Model } & \multirow[t]{2}{*}{$R^{2}$} & \multirow{2}{*}{$\begin{array}{c}\begin{array}{c}\text { Unstandardized } \\
\text { Coefficient }\end{array} \\
\text { B }\end{array}$} & & \multirow{2}{*}{$\begin{array}{c}\text { Standardized } \\
\text { Coefficient }\end{array}$} & \multirow[t]{2}{*}{$\mathbf{T}$} & \multirow[t]{2}{*}{ P Value } \\
\hline & & & & SE & & & \\
\hline \multirow{2}{*}{ Step 1} & Constant & & 50.43 & 2.29 & & 21.99 & 0.001 \\
\hline & Neuroticism & 0.31 & 0.43 & 0.09 & 0.57 & 4.86 & 0.001 \\
\hline \multirow{3}{*}{ Step 2} & Constant & & 40.25 & 4.23 & & 9.49 & 0.001 \\
\hline & Neuroticism & 0.40 & 0.44 & 0.08 & 0.58 & 5.26 & 0.001 \\
\hline & $\begin{array}{c}\text { Openness to } \\
\text { experience }\end{array}$ & & 0.32 & 0.11 & -0.30 & 2.78 & 0.008 \\
\hline
\end{tabular}

ferences of experiencing stress, depression, and anxiety. Higher neuroticism score is associated with irrational thinking, lower self-esteem, and utilizing ineffective coping strategies (McCrae \& John, 1992; Watson \& Hubbard, 1996). Thus it seems that neuroticism play an important role in predicting core self-evaluation. The results also stress on the role of conscientiousness factor in predicting core self-evaluation of normal women. Conscientiousness is described as the ability to be goal directed, lag immediate pleasure, think about the future, and have preference to follow social norms or outside expectations and act dutifully (John \& Srivastava, 1999; McCrae \& John, 1992). Theses characteristic are associated with the control, regulation, and direct individual's impulses. High scores on conscientiousness show a tendency to do planned behavior rather than spontaneous actions (Costa \& McCrae, 1992). Thus, the higher score in conscientiousness indicates better emotion regulation and less likelihood of trichotillomania.

Openness to experience was another important personality trait in this study. It is defined as intelligence, imaginative, perceptive, creative, flexible, and willingness to experience different things (McAdams, 1992). The core feature of openness to experience is a characteristic that is related to the ability of imagination, creativity, emotional and fantasy richness, as well as unconventionality. As a result, individuals with high scores in this subscale would experience lower psychological disorders. In line with literature that demonstrated a negative relationship between openness to experience and psychological disorders (Butler, 2000), results of this study showed a significant negative correlation between openness to experience and core self-evaluation of those with trichotillomania. These findings indicate that openness to experience is related to adoption of diversity and using appropriate coping strategies to regulate stressors, so the lower score in this subscale is predictor of core selfevaluation of women with trichotillomania (Jost, 2006).

Altogether, the findings of the current study indicate the difference between personality traits in predicting core self-evaluations of normal women and those with trichotillomania. Neuroticism predicts core self-evaluation in normal women and those with trichotillomania. Neuroticism is a vulnerability factor for many psychological disorders, so in the current study it negatively predicted core self-evaluation of normal women and positively correlated with core self-evaluation of women with trichotillomania. Also conscientiousness as a personality trait is associated with emotion regulation and has positive association with core self-evaluation of normal women. In addition, these findings showed that women with trichotillomania had lower openness to experience as a factor that showed lower ability for coping with stressors.

On the other hand, the other findings of this study showed that there are significant difference between normal women and those with trichotillomania. Women with trichotillomania had higher score in neuroticism and perfectionism (self-oriented perfectionism, otheroriented perfectionism, socially prescribed perfectionism, and total perfectionism) and lower score in core self-evaluation compared to normal women. These findings are supported by previous studies that showed higher association of core self-evaluation with wellbeing, life satisfaction, and lower possibility of mental disorder, (Danna \& Griffin, 1999; Schat, Kelloway, \& Desmarais, 2005), while higher perfectionism is related to many psychological disorders (Gámez, Chmielewski, Kotov, Ruggero, \& Watson., 2011).

In conclusion, based on the findings of this study, it can be argued that attention to some underlying factors such 
as perfectionism, evaluation of the self, and personality factors are more effective and important in the treatment of patients with trichotillomania. It is also important to mention several limitations of the study. First of all, it was a cross sectional study, so that we cannot infer causal relationships in our findings. Second, participants' data were collected by self-report method. Moreover, the sample of this study comprised only women so we cannot generalize the findings of this study to all population. Thus, it is recommended to include wider samples, both men and women, in future studies, to investigate the clinical correlations of trichotillomania, and perform longitudinal studies for comprehensive understanding of trichotillomania.

\section{Acknowledgments}

The authors are sincerely grateful to all study participants and those who helped us in conducting this research. This research did not receive any specific grant from funding agencies in the public, commercial, or notfor-profit sectors

\section{Conflict of Interest}

The authors declared no conflict of interests.

\section{References}

Besharat, M. A. (2005). [Exploratory analysis of relationship between perfectionism and character (Persian)]. Research in Clinical Psychology and Counselings, 6(1), 81-96.

Bleek, B., Montag, C., Faber, J., \& Reuter, M. (2011). Investigating personality in stuttering: Results of a case control study using the NEO-FFI. Journal of Communication Disorders, 44(2), 218-22. doi 10.1016/j.jcomdis.2010.11.001

Bolger, N., \& Zuckerman, A. (1995). A framework for studying personality in the stress process. Journal of Personality and Social Psychology, 69(5), 890-902. doi: 10.1037/0022-3514.69.5.890

Boudjouk, P. J., Woods, D. W., Miltenberger, R. G., \& Long, E. S (2000). Negative peer evaluation in adolescents: Effects of tic disorders and trichotillomania. Child \& Family Behavior Therapy, 22(1), 17-28. doi: 10.1300/j019v22n01_02

Brunborg, G. S. (2008). Core self-evaluations. European Psychologist, 13(2), 96-102. doi: 10.1027/1016-9040.13.2.96

Burnham, K. P., \& Anderson, D. R. (2004). Multimodel inference. Sociological Methods \& Research, 33(2), 261-304. doi $10.1177 / 0049124104268644$

Butler, J. C. (2000). Personality and emotional correlates of rightwing authoritarianism. Social Behavior and Personality: An International Journal, 28(1), 1-14. doi: 10.2224/sbp.2000.28.1.1
Chehri. A. (2004). [Evaluate the severity of anxiety in patients with trichotillomania in Kermanshah Daie Haj skin clinic (Persian)] (PhD thesis) Kermanshah: Medical University of Kermanshah.

Compas, B. E., Jaser, S. S., Dunbar, J. P., Watson, K. H., Bettis, A. H. Gruhn, M. A.,et al. (2013). Coping and emotion regulation from childhood to early adulthood: Points of convergence and divergence. Australian Journal of Psychology, 66(2), 71-81. doi: 10.1111/ ajpy.12043

Costa, P. T., \& McCrae, R. R. (1985). Hypochondriasis, neuroticism and aging: When are somatic complaints unfounded. American Psychologist, 40(1), 19-28. doi: 10.1037/0003-066x.40.1.19

Costa, P. T., \& McCrae, R. R. (1992). The NEO personality inventory manual. Odessa: Psychological Assessment Resources.

Costa, P., Jr., Terracciano, A., \& McCrae, R. R. (2001). Gender differences in personality traits across cultures: Robust and surprising findings. Journal of Personality and Social Psychology, 81(2), 322-31. doi: 10.1037/0022-3514.81.2.322

Danna, K., \& Griffin, R. W. (1999). Health and Well-Being in the Workplace: A Review and Synthesis of the Literature. Journal of Management, 25(3), 357-84. doi: 10.1177/014920639902500305

Diefenbach, G. J., Tolin, D. F., Meunier, S., \& Worhunsky, P. (2008). Emotion regulation and trichotillomania: A comparison of clinical and nonclinical hair pulling. Journal of Behavior Therapy and $E x-$ perimental Psychiatry, 39(1), 32-41. doi: 10.1016/j.jbtep.2006.09.002

Flessner, C. A., Conelea, C. A., Woods, D. W., Franklin, M. E. Keuthen, N. J., \& Cashin, S. E. (2008). Styles of pulling in trichotillomania: Exploring differences in symptom severity, phenomenology, and functional impact. Behaviour Research and Therapy, 46(3), 345-57. doi: 10.1016/j.brat.2007.12.009

Flett, G. L., \& Hewitt, P. L. (2002). Perfectionism: Theory, research, and treatment. Washington, D.C.: American Psychological Association. doi: $10.1037 / 10458-000$

Franklin, M. E., Flessner, C. A., Woods, D. W., Keuthen, N. J., Piacentini, J. C., Moore, P., et al. (2008). The child and adolescent trichotillomania impact project: Descriptive psychopathology, comorbidity, functional impairment, and treatment utilization. Journal of Developmental \& Behavioral Pediatrics, 29(6), 493-500. doi: 10.1097/dbp.0b013e31818d4328

Gámez, W., Chmielewski, M., Kotov, R., Ruggero, C., \& Watson, D. (2011). Development of a measure of experiential avoidance: The multidimensional experiential avoidance questionnaire. Psychological Assessment, 23(3), 692-713. doi: 10.1037/a0023242

Grant, J. E., Odlaug, B. L., \& Potenza, M. N. (2007). Addicted to hair pulling? How an alternate model of trichotillomania may improve treatment outcome. Harvard Review of Psychiatry, 15(2) 80-5. doi: 10.1080/10673220701298407

Hewitt, P. L., \& Flett, G. L. (2004). Multidimensional Perfectionism Scale (MPS): Technical manual. Toronto: MHS Assessments.

John, O. P., \& Srivastava, S. (1999). The big five trait taxonomy: History, measurement, and theoretical perspectives. In O. P. John, R W. Robins, \& L. A. Pervin (Eds.). Handbook of personality: Theory and Research (pp. 102-38). New York: Guilford Press; 1999.

Jost, J. T. (2006). The end of the end of ideology. American Psychologist, 61(7), 651-70. doi: 10.1037/0003-066x.61.7.651 
Judge, T. A., \& Ilies, R. (2002). Relationship of personality to performance motivation: A meta-analytic review. Journal of Applied Psychology, 87(4), 797-807. doi: 10.1037/0021-9010.87.4.797

Judge, T. A., Erez .A, Bono J. E., \& Thoresen, C. (2003). The core selfevaluations scale: Development of a measure. Personnel Psycholog, 56(2), 303-31. doi: 10.1111/j.1744-6570.2003.tb00152.x

Judge, T. A., Locke, E. A., Durham, C. C., \& Kluger, A. N. (1998) Dispositional effects on job and life satisfaction: The role of core evaluations. Journal of Applied Psychology, 83(1), 17-34. doi: 10.1037/0021-9010.83.1.17

Judge, T. A., Van Vianen, A. E. M., \& De Pater, I. E. (2004). Emotional stability, core self-evaluations, and job outcomes: A review of the evidence and an agenda for future research. Human Performance, 17(3), 325-46. doi: 10.1207/s15327043hup1703_4

Keuthen, N. J., Stein, D. J., \& Christenson, G. A. (2001). Help for hair pullers: Understanding and coping with trichotillomania. Oakland: New Harbinger Publications Incorporated.

Klag, S., \& Bradley, G. (2004). The role of hardiness in stress and illness: An exploration of the effect of negative affectivity and gender. British Journal of Health Psychology, 9(2), 137-61. doi: 10.1348/135910704773891014

Maddi, S. R. (1999). The personality construct of hardiness: I. Effects on experiencing, coping, and strain. Consulting Psychology Journal: Practice and Research, 51(2), 83-94. doi: 10.1037/1061-4087.51.2.83

Mansueto, C. S., Golomb, R. G., Thomas, A. M., \& Stemberger, R. M. T. (1999). A comprehensive model for behavioral treatment of trichotillomania. Cognitive and Behavioral Practice, 6(1), 23-43. doi: 10.1016/s1077-7229(99)80038-8

McAdams, D. P. (1992). The five-factor model in personality: A critical appraisal. Journal of Personality, 60(2), 329-61. doi: 10.1111/ j.1467-6494.1992.tb00976.x

McCrae, R. R., \& John, O. P. (1992). An introduction to the five-factor model and its applications. Journal of Personality, 60(2), 175-215. doi: 10.1111/j.1467-6494.1992.tb00970.x

Millon, T., Millon, C. M., Meagher, S. E., Grossman, S. D., \& Ramnath, R. (2012). Personality disorders in modern life. New Jersey: John Wiley \& Sons.

Moroz, M., \& Dunkley, D. M. (2015). Self-critical perfectionism and depressive symptoms: Low self-esteem and experiential avoidance as mediators. Personality and Individual Differences, 87, 174-9. doi: 10.1016/j.paid.2015.07.044

PÉLissier, M. C., \& O'Connor, K. (2004). Cognitive-behavioral treatment of trichotillomania, targeting perfectionism. Clinical Case Studies, 3(1), 57-69. doi: 10.1177/1534650103258973

Penzel, F. (2003). The hair-pulling problem: A complete guide to trichotillomania. NewYork: Oxford University Press.

Rosopa, P. J., \& Schroeder, A. N. (2009). Core self-evaluations interact with cognitive ability to predict academic achievement. Personality and Individual Differences, 47(8), 1003-6. doi: 10.1016/j. paid.2009.07.028

Rufer, M., Bamert, T., Klaghofer, R., Moritz, S., Schilling, L., \& Weidt, S. (2014). Trichotillomania and emotion regulation: Is symptom severity related to alexithymia. Psychiatry Research, 218(1-2), 161-5. doi:10.1016/j.psychres.2014.03.029
Schat, A. C. H., Kelloway, E. K., \& Desmarais, S. (2005). The Physical Health Questionnaire (PHQ): Construct Validation of a SelfReport Scale of Somatic Symptoms. Journal of Occupational Health Psychology, 10(4), 363-81. doi: 10.1037/1076-8998.10.4.363

Schultz, D. P., \& Schultz, S. E. (2016). Theories of personality. Boston: Cengage Learning.

Sharati, M., Garosi, M. T., Babapour, J. (2010). [Efficiency of the core self evaluations model in predicting of subjective well-being (Persian)]. Research in Psychological Health, 3(4), 5-16.

Shusterman, A., Feld, L., Baer, L., \& Keuthen, N. (2009). Affective regulation in trichotillomania: Evidence from a large-scale in ternet survey. Behaviour Research and Therapy, 47(8), 637-44. doi 10.1016/j.brat.2009.04.004

Soofiani, H. (2007). Investigation of the relationship between char acter and aspects of perfectionism and general health, Tabriz, Iran.

Spector, P. E., Zapf, D., Chen, P., \& Frese, M. (2000). Why negative affectivity should not be controlled in job stress research Don't throw the baby out with the bath water. Journal of Organizational Behavior, 21(1), 79-95. doi: 10.1002/(sici)10991379(200002)21:1<79::aid-job964>3.0.co;2-g

Stoeber, J., \& Childs, J. H. (2010). The assessment of self-oriented and socially prescribed perfectionism: Subscales make a difference. Journal of Personality Assessment, 92(6), 577-85. doi: 10.1080/00223891.2010.513306

Tay, Y. K., Levy, M. L., \& Metry, D. W. (2004). Trichotillomania in childhood: Case series and review. Pediatrics, 113(5), 494-8. doi: 10.1542/peds.113.5.e494

Teng, E. J., Woods, D. W., Twohig, M. P., \& Marcks, B. A. (2002). Bodyfocused repetitive behavior problems: Prevalence in a nonreferred population and differences in perceived somatic activity. Behavior Modification, 26(3), 340-60. doi: 10.1177/01445502026003003

Tolin, D. F., Franklin, M. E., Diefenbach, G. J., Anderson, E., \& Meunier, S. A. (2007). Pediatric trichotillomania: Descriptive psychopathology and an open trial of cognitive behavioral therapy. Cognitive Behaviour Therapy, 36(3), 129-44. doi: $10.1080 / 16506070701223230$

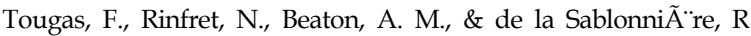
(2005). Policewomen acting in self-defense: Can psychological disengagement protect self-esteem from the negative outcomes of relative deprivation. Journal of Personality and Social Psychology, 88(5), 790-800. doi: 10.1037/0022-3514.88.5.790

Watson, D., \& Hubbard, B. (1996). Adaptational style and dispositional structure: Coping in the context of the five-factor model. Journal of Personality, 64(4), 737-74. doi: 10.1111/j.1467-6494.1996. tb00943.x

Woods, D. W., Flessner, C. A., Franklin, M. E., Keuthen, N. J., Goodwin, R. D., Stein, D. J. et al. (2006). The trichotillomania impact project (TIP). The Journal of Clinical Psychiatry, 67(12), 1877-1888. doi:10.4088/jcp.v67n1207

Yan, X., \& Su, J. (2012). Core self-evaluations mediators of the influence of social support on job involvement in hospital nurses. Social Indicators Research, 113(1), 299-306. doi: 10.1007/ s11205-012-0093-x 
